\title{
Edge Contrast of the FLAIR Hyperintense Region Predicts Survival in Patients with High-Grade Gliomas following Treatment with Bevacizumab
}

\author{
(D) N. Bahrami, DD. Piccioni, (D). Karunamuni, (D).-H. Chang, (DN. White, DR. Delfanti, (D)T.M. Seibert, (D).A. Hattangadi-Gluth, \\ (D)A. Dale, (D) N. Farid, and (D)C.R. McDonald

\begin{abstract}
BACKGROUND AND PURPOSE: Treatment with bevacizumab is standard of care for recurrent high-grade gliomas; however, monitoring response to treatment following bevacizumab remains a challenge. The purpose of this study was to determine whether quantifying the sharpness of the fluid-attenuated inversion recovery hyperintense border using a measure derived from texture analysis-edge contrast -improves the evaluation of response to bevacizumab in patients with high-grade gliomas.
\end{abstract}

MATERIALS AND METHODS: MRIs were evaluated in 33 patients with high-grade gliomas before and after the initiation of bevacizumab. Volumes of interest within the FLAIR hyperintense region were segmented. Edge contrast magnitude for each VOI was extracted using gradients of the 3D FLAIR images. Cox proportional hazards models were generated to determine the relationship between edge contrast and progression-free survival/overall survival using age and the extent of surgical resection as covariates.

RESULTS: After bevacizumab, lower edge contrast of the FLAIR hyperintense region was associated with poorer progression-free survival $(P=.009)$ and overall survival $(P=.022)$ among patients with high-grade gliomas. Kaplan-Meier curves revealed that edge contrast cutoff significantly stratified patients for both progression-free survival (log-rank $\chi^{2}=8.3, P=.003$ ) and overall survival (log-rank $\chi^{2}=5.5, P=$ .019).

CONCLUSIONS: Texture analysis using edge contrast of the FLAIR hyperintense region may be an important predictive indicator in patients with high-grade gliomas following treatment with bevacizumab. Specifically, low FLAIR edge contrast may partially reflect areas of early tumor infiltration. This study adds to a growing body of literature proposing that quantifying features may be important for determining outcomes in patients with high-grade gliomas.

ABBREVIATIONS: $\mathrm{EC}$ = edge contrast; $\mathrm{GBM}=$ glioblastoma; $\mathrm{GTR}=$ gross total resection; $\mathrm{HGG}$ = high-grade glioma; $\mathrm{MSRS}=$ Maximally Selected Rank Statistics; $\mathrm{OS}=$ overall survival; PFS = progression-free survival; RANO = Response Assessment in Neuro-Oncology; $\mathrm{STR}=$ subtotal resection; $\mathrm{VOL}=$ volume

$\mathrm{H}$ igh-grade glioma (HGG) is among the most common primary brain tumors in adults and is associated with a poor prognosis. ${ }^{1}$ Moreover, monitoring the efficacy of different therapeutic agents in patients with HGG remains a challenge. The Response Assessment in Neuro-Oncology (RANO) and the Macdonald criteria are the current standards for response assessment

Received October 17, 2017; accepted after revision February 7, 2018.

From the Center for Multimodal Imaging and Genetics (N.B., N.W., C.R.M.), Department of Psychiatry (N.B., Y.-H.C., C.R.M.), Department of Radiology (N.B., N.W., R.D., A.D., N.F., C.R.M.), Multimodal Imaging Laboratory (N.B., N.W., A.D., C.R.M.), Department of Neurosciences (D.P., A.D., N.F.), and Department of Radiation Medicine (R.K., T.M.S., J.A.H.-G.), University of California, San Diego, La Jolla, California.

We acknowledge funding from National Institutes of Health grants R01NS065838 (C.R.M.), UL1TR000100 (J.A.H.-G.), and KL2TR00144 (J.A.H.-G.); American Cancer Society Award ACS-IRG 70-002 (J.A.H.-G.); and American Cancer Society RSG-15-229-01CCE (C.R.M).

Please address correspondence to Naeim Bahrami, PhD, Center for Multimodal Imaging and Genetics, University of California, San Diego, 9452 Medical Center Dr, La Jolla, CA 92037: e-mail: nabahrami@ucsd.edu, naeim.bahrami@gmail.com; @Naeimbah to therapy in patients with HGG and have been shown to correlate with overall survival (OS). ${ }^{2-4}$ However, determining tumor response becomes particularly challenging following treatment with antiangiogenic agents such as bevacizumab, due to the tendency of these agents to decrease contrast enhancement and T2 fluid-attenuated inversion recovery hyperintensity in the absence of a true tumor response. ${ }^{2,5-11}$ Recent data have demonstrated that the RANO criteria may lead to earlier detection of tumor progression following treatment with bevacizumab because they take into account nonenhancing tumor progression. ${ }^{12-14}$ In a recent study, the RANO criteria were shown to be more sensitive to tumor progression than the Macdonald criteria with the detection of at least $35 \%$ of patients in an HGG cohort who had nonenhancing tumor

\footnotetext{
- Indicates open access to non-subscribers at www.ajnr.org

三 Indicates article with supplemental on-line table.

Indicates article with supplemental on-line photos.

http://dx.doi.org/10.3174/ajnr.A5620
}

AJNR Am J Neuroradiol 39:1017-24 Jun 2018 www.ajnr.org 
progression in T2 FLAIR regions. ${ }^{14}$ Thus, the evaluation of T2 FLAIR changes may be critical to the detection of early tumor progression following treatment with antiangiogenic agents.

Despite a growing appreciation of the importance of abnormal findings on T2 FLAIR for evaluating tumor response and progression, these features are typically evaluated qualitatively. ${ }^{14-16}$ This type of assessment relies on considerable reader expertise because T2 FLAIR changes can also reflect tumor growth or other processes that result in $\mathrm{T} 2$ prolongation, including radiation effects, edema, ischemic injury, infection, seizures, and postoperative gliosis. Given that subjectively differentiating such entities may be difficult or vary across experts, a quantitative assessment of T2 FLAIR abnormalities could aid in distinguishing early nonenhancing tumor progression from treatment-related changes.

Recent studies have shown that specific features of the FLAIR signal, including increased nodularity, blurring of tumor borders, and mass effect may improve the detection of tumor progression. ${ }^{17-19}$ These studies and others have demonstrated that specific FLAIR phenotypes alone or in combination with other imaging features (eg, contrast enhancement, perfusion) are predictive of survival following treatment with bevacizumab. ${ }^{12,20-22}$

Nowosielski et al in $2014^{20}$ found that "T2-circumscribed" tumors, characterized by a bulky appearance and sharp FLAIR borders, are associated with poorer survival, whereas Norden et al in $2008^{10}$ suggested that a more infiltrative T2 FLAIR pattern may represent a more aggressive tumor. These studies suggest that sharpness of T2 FLAIR borders could have prognostic value following treatment with bevacizumab and provide a valuable biomarker of tumor progression. However, there appears to be discrepancy in the literature as to whether a "well-defined" versus "vague, ill-defined" FLAIR border indicates a poorer prognosis. Given the variability in terminology used in these qualitative studies and the ambiguous criteria for defining FLAIR borders, quantitative imaging metrics that are standardized across studies and independent of interrater and intrarater bias are needed to systematically address this question.

In this study, we used texture analysis to examine whether quantifying the sharpness of the FLAIR hyperintense border (ie, edge contrast $[\mathrm{EC}]$ ) improves the evaluation of response to bevacizumab in patients with HGG. EC is a type of texture analysis that has been shown in previous studies to distinguish well-defined versus vague borders in grade II and III gliomas and has been validated against neuroradiologic reads. ${ }^{23}$ On the basis of our previous work demonstrating that "ill-defined" FLAIR borders are associated with poorer survival in patients with grade II and III gliomas, ${ }^{24}$ we hypothesized that patients with low EC (ie, vague borders) of the FLAIR hyperintense region will have poorer progression-free survival (PFS) and OS compared with patients with high EC (ie, sharp borders). We also hypothesized that EC will be a stronger predictor of PFS and OS than the volume of the FLAIR or contrast-enhancement region following treatment with bevacizumab.

\section{MATERIALS AND METHODS \\ Patients}

This retrospective study was approved by the institutional review board. From 2011 to 2015, sixty patients with HGGs were identi- fied at our institution who had both pre- and postbevacizumab MRIs, including T1 pre- and postcontrast and 3D-FLAIR. Patients were excluded if they received bevacizumab for any other reason than recurrent tumor (eg, radiation necrosis), the baseline scan was $>60$ days before initiating bevacizumab therapy or the follow-up scan was $>60$ days after initiation of treatment, there were significant artifacts on imaging, or the imaging sequence was not available at 1 of the 2 time points (pre- and postbevacizumab). Thirty-three patients with HGGs met the inclusion criteria to form the final study cohort (On-line Table). Twenty-nine patients had glioblastomas (GBMs), 2 patients had anaplastic astrocytomas, and 2 patients had anaplastic oligodendrogliomas. The final cohort included 23 men and 10 women; the average age was 55 years with a range of $31-74$ years. All patients had at least 1 operation before treatment with bevacizumab, with the most recent operation before the initiation of bevacizumab being a subtotal resection (STR, $n=20$ ) or a gross total resection (GTR, $n=13$ ). All patients received chemoradiation with temozolomide (alone or in combination with other agents) as the initial treatment. On recurrence, 15 patients received bevacizumab monotherapy, whereas 18 received bevacizumab in combination with other agents (carboplatin, irinotecan, lomustine [CCNU], temozolomide). No MRIs obtained within the first 60 days following the operation were included, to avoid immediate postsurgical effects such as hemorrhage. The patients included in this study represented a subset (33 of 40) of the patients reported in a previous publication that examined the utility of advanced diffusion imaging (ie, restriction spectrum imaging) for the evaluation of the response to bevacizumab. ${ }^{25}$

\section{MR Imaging and Preprocessing}

All the MR imaging scans were acquired on a 3T Signa Excite HDx scanner (GE Healthcare, Milwaukee, Wisconsin) using an 8 -channel head coil. The imaging protocol included pre- and postgadolinium $3 \mathrm{D}$ volumetric $\mathrm{T} 1$-weighted inversion recovery echo-spoiled gradient-echo imaging with $\mathrm{TE} / \mathrm{TR}=2.8 / 6.5 \mathrm{~ms}$, $\mathrm{TI}=450 \mathrm{~ms}$, flip angle $=8^{\circ}, \mathrm{FOV}=24 \mathrm{~cm}$, voxel size $=0.93 \times$ $0.93 \times 1.2 \mathrm{~mm}$; and a $3 \mathrm{D}$ T2-weighted FLAIR sequence with $\mathrm{TE} / \mathrm{TR}=126 / 6000 \mathrm{~ms}, \mathrm{TI}=863, \mathrm{FOV}=24 \mathrm{~cm}$, voxel size $=$ $0.93 \times 0.93 \times 1.2 \mathrm{~mm}$.

Before analysis, raw data were corrected for bias field and distortion. ${ }^{26}$ Then, correction for patient motion was performed using in-house software. The pre- and postcontrast 3D inversion recovery echo-spoiled gradient-echo and FLAIR images were registered to each other using rigid body registration at each of the 2 time points.

\section{Volumes of Interest}

Contrast-enhanced volumes $\left(\mathrm{CE}_{\mathrm{VOL}}\right)$ and FLAIR hyperintense volumes $\left(\right.$ FLAIR $_{\mathrm{VOL}}$ ) were segmented semiautomatically (Amira software package; Visage Imaging, San Diego, California) on the coregistered FLAIR and postcontrast 3D inversion recovery echo-spoiled gradient-echo images acquired both pre- and posttreatment, while regions of necrosis and the resection cavity were excluded. The final FLAIR $_{\mathrm{VOL}}$ also excluded the $\mathrm{CE}_{\mathrm{VOL}}$ to obtain an estimate of the nonenhancing lesion. All volumes of interest were drawn by 2 trained image analysts 
(R.D. and N.F.) and approved by a board-certified neuroradiologist with expertise in neuro-oncology. ${ }^{2}$

\section{Edge Contrast Calculation}

The following postprocessing and image-enhancement steps were applied to the FLAIR $_{\mathrm{VOL}}$ to extract the lesion surfaces and calculate the EC (On-line Figs 1 and 2, which present the flowchart for the EC extraction). We applied 3D analysis to the lesions to enhance the local precision and decrease the partial volume effect. ${ }^{27-30}$

Step 1) Morphologic operations of erosion and dilation were

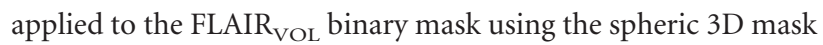
$(r=3)$ to remove the holes and small islands (On-line Fig 1A, $-B)$.

Step 2) The contour of the FLAIR $_{\mathrm{VOL}}$ binary mask was extracted in $3 \mathrm{D}$, indexing the surface of the $\mathrm{FLAIR}_{\mathrm{VOL}}$ lesion.

Step 3) The gradients of the FLAIR image were calculated in $3 \mathrm{D}$ using the first derivative of the FLAIR image (On-line Fig 1C).

Step 4) The gradients of the FLAIR $_{\mathrm{VOL}}$ from step 3 were overlaid on the surface of the 3D binary mask from step 2 to create the hyperintense surface with the initial EC (On-line Fig 1D). EC is defined as the gradient magnitude of the lesion edges.

Step 5) The initial EC was modified by removing the pixels with the highest $10 \%$ intensity to minimize the effect of edge magnitude arising from the CSF and skull (On-line Fig $1 E,-F)$.

Step 6) Four EC parameters were calculated for each edge magnitude layer; $\mathrm{EC}_{100 \%}=$ average magnitude of all points on the edge, $\mathrm{EC}_{75 \%}=$ average magnitude of the lowest $75 \%$ of points, $\mathrm{EC}_{50 \%}=$ average magnitude of the lowest half of points, and $\mathrm{EC}_{25 \%}=$ average magnitude of the lowest $25 \%$ of points. This approach was selected to determine whether EC of the whole FLAIR border versus a subset of the FLAIR border with lower EC

Table 1: Summary of the imaging parameters pre- and postbevacizumab

\begin{tabular}{lccc}
\hline Parameter & $\begin{array}{c}\text { Prebevacizumab } \\
\text { Mean (SD) } \times 10^{3}\end{array}$ & $\begin{array}{c}\text { Postbevacizumab } \\
\text { Mean (SD) } \times 10^{3}\end{array}$ & $\begin{array}{c}\boldsymbol{P} \text { Value } \\
\text { ( } \boldsymbol{T} \text { Value) }\end{array}$ \\
\hline $\mathrm{EC}_{100 \%}$ & $2.52(0.57)$ & $2.43(0.57)$ & $.256(1.15)$ \\
$\mathrm{EC}_{75 \%}$ & $1.91(0.53)$ & $1.77(0.47)$ & $.281(1.08)$ \\
$\mathrm{EC}_{50 \%}$ & $1.51(0.48)$ & $1.38(0.40)$ & $.277(1.11)$ \\
$\mathrm{EC}_{25 \%}$ & $1.06(0.38)$ & $0.98(0.30)$ & $.184(1.35)$ \\
FLAIR $_{\mathrm{VOL}}{ }^{a}$ & $121.88(70.68)$ & $77.317(38.55)$ & $.002(4.28)$ \\
$\mathrm{CE}_{\mathrm{VOL}}$ & $24.90(15.26)$ & $9.16(9.17)$ & $<.001(6.34)$ \\
\hline${ }^{\mathrm{a}} \mathrm{P}<.05$. & & &
\end{tabular}

(ie, areas that could represent local tumor infiltration) predicts PFS/OS postbevacizumab. These 4 parameters were calculated on each scan (pre- and postbevacizumab) for each patient. The change in EC was defined as the change in EC parameters between the pre- and postbevacizumab scan.

\section{Progression-Free Survival and Overall Survival}

PFS and OS were calculated for all patients from the date of initiation of bevacizumab to tumor progression or death, respectively. Tumor progression was verified by direct pathologic confirmation when available or evidence of progression based on MR imaging and neurologic status jointly determined by a board-certified neuroradiologist (N.F.) and board-certified neuro-oncologist (D.P.) using the RANO criteria.

\section{Statistics}

Paired $t$ tests were conducted to compare EC, FLAIR ${ }_{\mathrm{VOL}}$, and $\mathrm{CE}_{\mathrm{VOL}}$ parameters pre- and postbevacizumab. Multivariate Cox proportional hazards models that included age and the extent of the resection (ie, subtotal resection versus gross total resection) as covariates were used to determine the relationship between each EC measure, FLAIR ${ }_{\mathrm{VOL}}$, and $\mathrm{CE}_{\mathrm{VOL}}$ postbevacizumab and the pre- and postchange in each of these measures with PFS/OS. Maximally Selected Rank Statistics (MSRS) were used to identify optimal cutoff points for EC that stratified patients according to PFS/OS. Kaplan-Meier survival analyses were conducted on the basis of the subgroups obtained from the MSRS split and compared using a log-rank test. In the case of no progression or death, the event time was censored at the date of last follow-up. In all cases, 2 -tailed $P<.05$ was considered statistically significant.

\section{RESULTS}

\section{Pre- to Postbevacizumab Changes in EC, FLAIR vov $_{\text {v }}$ and $\mathrm{CE}_{\text {vol }}$}

At the group level, there were no significant differences between pre- and postbevacizumab EC parameters. However, inspection of individual subject data revealed that $37 \%$ of patients had a $\geq 10 \%$ decrease in $\mathrm{EC}_{100 \%}$ postbevacizumab, whereas $46 \%$ of patients had $\mathrm{a} \geq 10 \%$ decrease in $\mathrm{EC}_{75 \%}, \mathrm{EC}_{50 \%}$, and $\mathrm{EC}_{25 \%}$. There was a significant decrease in both $\mathrm{CE}_{\mathrm{VOL}}[t(32)=6.34, P<.001]$ and FLAIR $_{\text {VOL }}[t(32)=4.28, P<.001]$ at the group level (Table 1 ).

Table 2: Summary of the multivariate CPH models with age and surgical extent (subtotal, gross total resection) as covariates

\begin{tabular}{|c|c|c|c|c|c|c|c|}
\hline \multirow[b]{2}{*}{ Edge } & \multicolumn{3}{|c|}{ PFS } & \multicolumn{3}{|c|}{ OS } & \multirow[b]{2}{*}{$95 \% \mathrm{Cl}$} \\
\hline & Time & $P$ Value & HR & $95 \% \mathrm{Cl}$ & $P$ Value & HR & \\
\hline $\mathrm{EC}_{100 \%}$ & Postbevacizumab & $.009^{\mathrm{a}}$ & 0.37 & $0.18-0.78$ & $.046^{b}$ & 0.42 & $0.18-0.98$ \\
\hline $\mathrm{EC}_{75 \%}$ & Postbevacizumab & $.013^{\mathrm{b}}$ & 0.33 & $0.13-0.79$ & $.041^{\mathrm{b}}$ & 0.34 & $0.12-0.96$ \\
\hline $\mathrm{EC}_{50 \%}$ & Postbevacizumab & $.015^{b}$ & 0.29 & $0.10-0.78$ & $.026^{b}$ & 0.25 & $0.07-0.85$ \\
\hline $\mathrm{EC}_{25 \%}$ & Postbevacizumab & $.018^{b}$ & 0.21 & $0.05-0.77$ & $.022^{b}$ & 0.16 & $0.03-0.77$ \\
\hline FLAIR $_{\mathrm{VOL}}$ & Postbevacizumab & .872 & 1.000 & $1.000-1.000$ & .204 & 1.000 & $1.000-1.000$ \\
\hline $\mathrm{CE}_{\mathrm{VOL}}$ & Postbevacizumab & .758 & 1.000 & $1.000-1.000$ & .258 & 1.000 & $1.000-1.000$ \\
\hline$\Delta \mathrm{EC}_{100 \%}$ & Pre- and postbevacizumab & $.018^{\mathrm{b}}$ & 2.81 & $1.92-6.65$ & $.033^{\mathrm{b}}$ & 2.98 & $1.09-8.16$ \\
\hline$\Delta \mathrm{EC}_{75 \%}$ & Pre- and postbevacizumab & $.039^{b}$ & 2.75 & $1.05-7.19$ & .050 & 3.06 & $0.99-9.39$ \\
\hline$\Delta \mathrm{EC}_{50 \%}$ & Pre- and postbevacizumab & .058 & 2.91 & 0.96-8.08 & .054 & 3.54 & $0.97-12.88$ \\
\hline$\Delta \mathrm{EC}_{25 \%}$ & Pre- and postbevacizumab & .067 & 3.74 & $0.090-15.42$ & .056 & 4.76 & $0.95-23.64$ \\
\hline$\Delta$ FLAIR $_{\mathrm{VOL}}$ & Pre- and postbevacizumab & .360 & 1.000 & $1.000-1.000$ & .487 & 1.000 & $1.000-1.000$ \\
\hline$\Delta \mathrm{CE}_{\mathrm{VOL}}$ & Pre- and postbevacizumab & .951 & 1.000 & $1.000-1.000$ & .926 & 1.000 & $1.000-1.000$ \\
\hline
\end{tabular}

Note:- $\mathrm{CPH}$ indicates Cox proportional hazards; HR, hazard ratio.

a $P<.01$.

${ }^{\mathrm{b}} \mathrm{P}<.05$. 


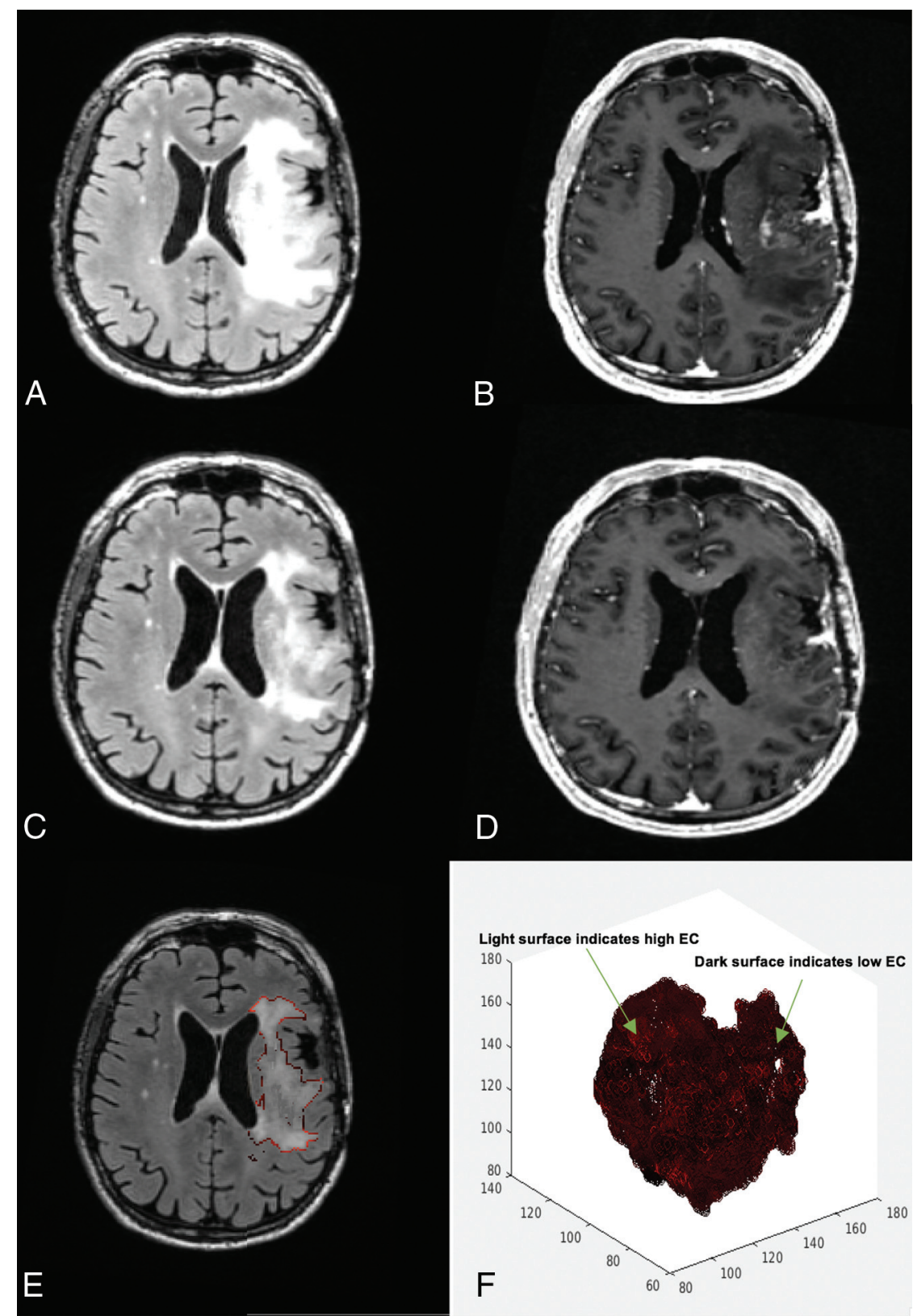

FIG 1. A 58-year-old man's MR imaging post-subtotal resection with low edge contrast. The patient had a poor survival estimation, with a PFS of 1.8 months and OS of 7.3 months. A, FLAIR prebevacizumab. $B, T 1$ postcontrast prebevacizumab. $C$, FLAIR postbevacizumab. $D$, T1 postcontrast postbevacizumab. E, Overlay of the EC contour over the postbevacizumab FLAIR image. $F$, $3 \mathrm{D}$ presentation of the surface of the hyperintense region. Darker areas on the surface indicate lower $\mathrm{EC} /$ more indistinct border, whereas the lighter areas toward red show higher EC/more distinct border.

Seventy-six percent of patients showed a $\geq 50 \%$ decrease in $\mathrm{CE}_{\mathrm{VOL}}$, whereas an additional $6 \%$ of patients showed a decrease of $25 \%-50 \%$. Thirty percent of the patients showed a corresponding decrease of $\geq 50 \%$ in FLAIR $_{\mathrm{VOL}}$ surrounding the contrast-enhancement region, whereas an additional $18 \%$ showed a decrease of $25 \%-50 \%$ in FLAIR $_{\mathrm{VOL}}$ following bevacizumab.

There were no significant associations between change in any of the EC parameters and change in FLAIR $_{\mathrm{VOL}}$ or $\mathrm{CE}_{\mathrm{VOL}}$ (all $P$ values $>.05)$. However, post hoc analysis revealed that $53 \%$ of patients with high postbevacizumab $\mathrm{EC}_{100 \%}\left(\mathrm{EC}_{100 \%}>\right.$ medi$\left.\operatorname{an}_{\mathrm{EC} 100 \%}=2117.62\right)$ had large decreases in $\mathrm{CE}_{\mathrm{VOL}}\left(\Delta \mathrm{CE}_{\mathrm{VOL}}>\right.$
$71.2 \%)$ and $59 \%$ had large decreases in FLAIR $_{\mathrm{VOL}}\left(\Delta\right.$ FLAIR $\left._{\mathrm{VOL}}>32.3 \%\right)$. In addition, $38 \%$ and $50 \%$ of patients with low postbevacizumab $\mathrm{EC}_{100 \%}$ had large decreases in $\mathrm{CE}_{\mathrm{VOL}}$ and FLAIR $_{\mathrm{VOL}}$, respectively.

\section{Survival Analysis}

Median PFS following initiation of bevacizumab was 3.94 months (with 31 patients meeting the PFS end point), whereas the median OS following initiation of bevacizumab was 6.80 months (with 25 patients meeting the OS end point). Multivariate Cox proportional hazards models indicated that all EC thresholds postbevacizumab and $\Delta \mathrm{EC}_{100 \%}$ and $\Delta \mathrm{EC}_{75 \%}$ pre- to postbevacizumab were associated with poorer PFS, whereas all EC thresholds were associated with OS (Table 2). Post-EC $100 \%$ showed the highest association with PFS, whereas $\Delta \mathrm{EC}_{75 \%}$ showed the highest association with OS. However, the overlap in confidence intervals among the EC parameters suggests that they did not significantly differ from one another in their associations with PFS or OS. In both cases, lower EC values were associated with poorer survival. Pre- and postbevacizumab thresholds showed similar associations with PFS/OS in which $\Delta \mathrm{EC}_{100 \%}$ showed the highest association with PFS and $\triangle \mathrm{EC}_{75 \%}$ showed the highest association with OS. There were no associations between FLAIR $_{\mathrm{VOL}}$ and $\mathrm{CE}_{\mathrm{VOL}}$ with $\mathrm{PFS} / \mathrm{OS}$ postbevacizumab or pre- and postbevacizumab. Figure 1 shows an example of a patient with low EC and poor PFS/OS, whereas Fig 2 shows an example of a patient with high EC and good PFS/OS.

MSRS was used to identify optimal cutoff points for post-EC values that stratified the patients according to PFS/ OS. A post-EC $\mathrm{E}_{100 \%}$ value of 2750.9 was determined to best stratify patients for PFS and OS. Kaplan-Meier survival curves revealed that the post$\mathrm{EC}_{100 \%}$ cutoff significantly separated the groups for PFS [log-rank $\chi^{2}(1)=8.3, P=.003$ ] (Fig 3A). Similarly, the post-EC ${ }_{100 \%}$ cutoff significantly stratified the groups for OS $\left[\log\right.$-rank $\chi^{2}(1)=5.5$, $P=.019]$. Both analyses categorized 8 patients with better $\mathrm{PFS} / \mathrm{OS}$ and 25 patients with poorer PFS/OS (Fig $3 B$ ). Given the small number of patients with better OS and PFS, a median split was also used to divide patients into more balanced groups. Similarly, the post-EC ${ }_{100 \%}$ cutoff significantly stratified groups for PFS and OS. 


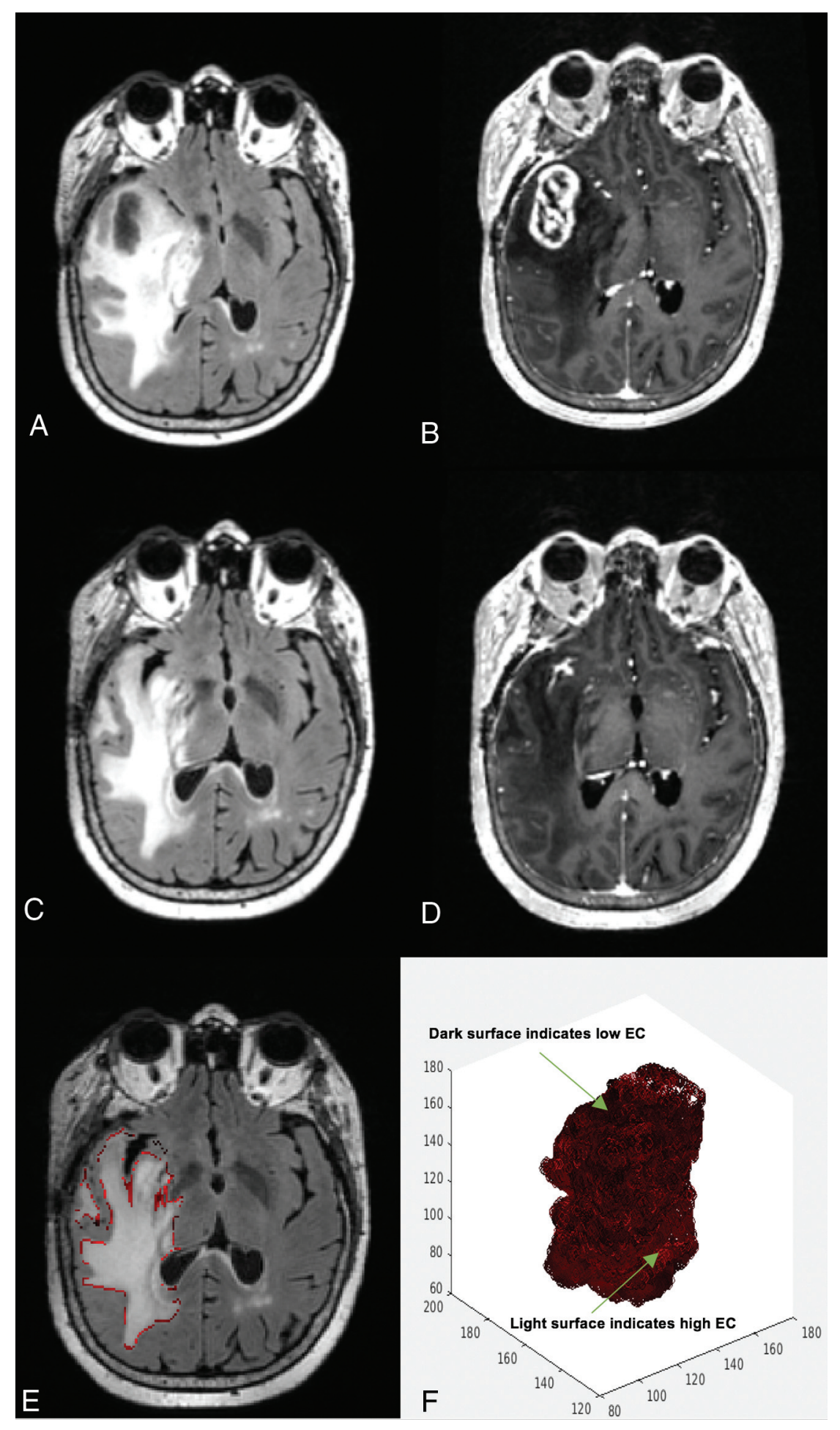

FIG 2. A 60-year-old woman's MR imaging post-subtotal resection with high edge contrast. The patient had a high survival estimation with PFS of 11.5 months and OS of 13.6 months. A, FLAIR prebevacizumab. $B, T 1$ postcontrast prebevacizumab. C, FLAIR postbevacizumab. $D, T 1$ postcontrast postbevacizumab. E, Overlay of the EC contour over the postbevacizumab FLAIR image. $F$, 3D presentation of the surface of the hyperintense region. Darker areas on the surface indicate lower EC and more indistinct border, whereas the lighter areas toward red show higher EC and more distinct border.

\section{DISCUSSION}

In this study, we introduce a new, quantitative imaging technique for characterizing the FLAIR border in patients with HGG and highlight a clinical scenario in which it may have prognostic value.
We demonstrate that patients with vague, ill-defined FLAIR borders (low EC) have poorer PFS and OS compared with patients with sharper FLAIR borders (high EC). We also demonstrate that most patients with sharper EC postbevacizumab had a greater decrease in the volume of the contrast enhancement and FLAIR regions despite the lack of a direct association among these measures. However, EC was the only imaging measure associated with PFS/OS, and this association was robust to the EC threshold used. These findings are in line with previous research suggesting that neither FLAIR nor contrast-enhancement volumes are significant predictors of PFS/OS following bevacizumab. ${ }^{25,31}$ Rather, quantitative estimates of FLAIR border patterns may have the potential to serve as a reliable biomarker for nonenhancing tumor progression in patients with HGG following treatment with bevacizumab.

In the current study, EC is a measure of the sharpness of the FLAIR hyperintense border and provides a quantitative measure that is not biased by inter- and intrarater variability. Although it is not clear what various EC levels of the FLAIR sharpness represent biologically, tumor infiltration following treatment with bevacizumab is one possible mechanism that reduces EC. Previous studies have shown that antiangiogenic therapy leads to the use of pre-existing cerebral blood vessels by tumor cells-a process known as vascular cooption-and consequently results in increased infiltrative growth. As a result, nonenhancing regions of FLAIR hyperintensity in patients with HGGs undergo a shift to an infiltrative pattern defined, in part, by a more ill-defined or vague FLAIR border. ${ }^{10,32,33}$ The association between an "invasive" FLAIR border and infiltrative tumor growth ${ }^{34}$ has been validated in histologic specimens of patients treated with bevacizumab. ${ }^{32}$ However, the sharpness of the FLAIR border may also be partially unmasked by decreases in edema, despite the lack of an association between changes in EC and FLAIR volumes. Thus, it is possible that changes in both edema and tumor infiltration influenced our postbevacizumab EC measures. Nevertheless, we provide initial evidence that this FLAIR border pattern can be quantified on 3D imaging 

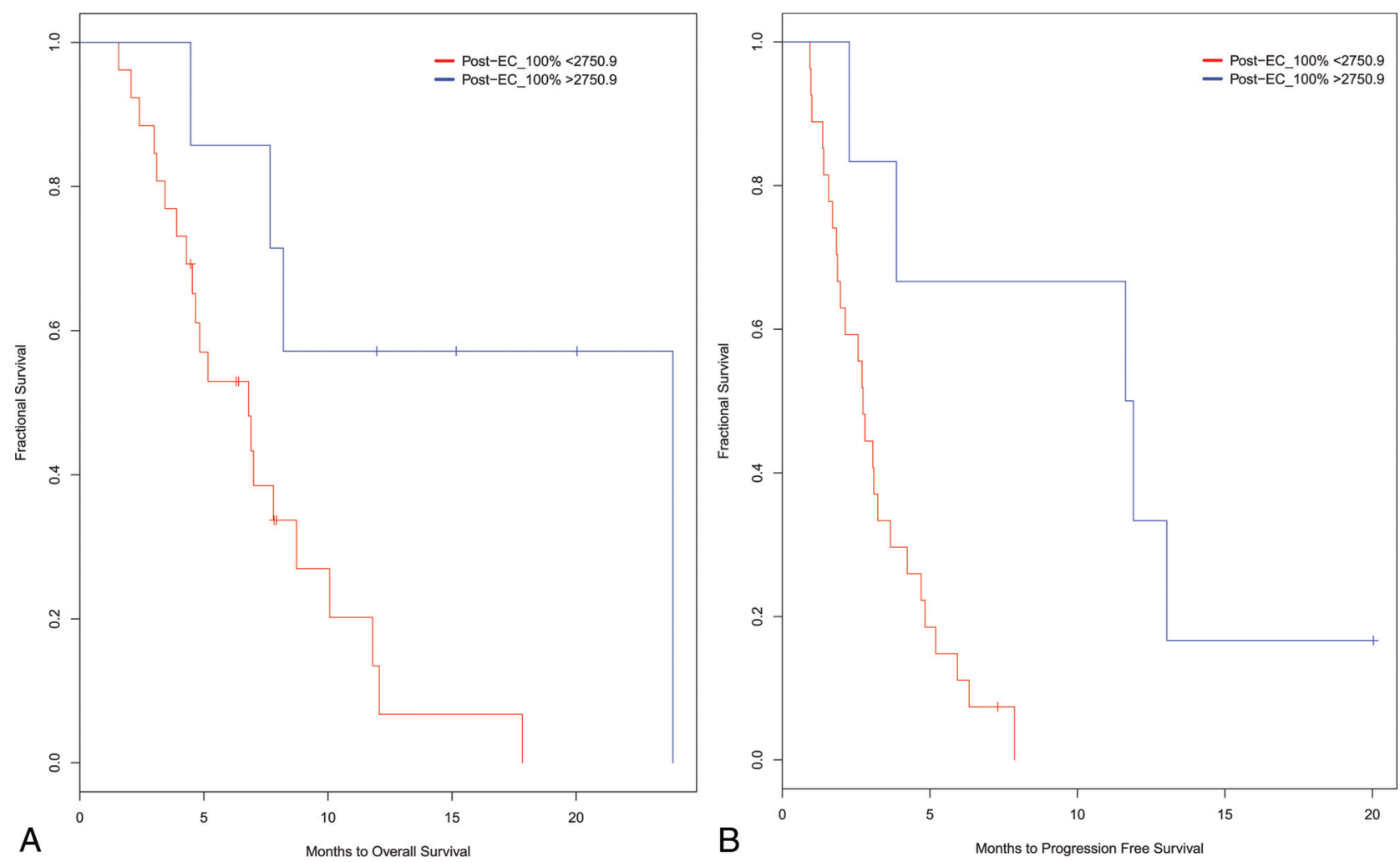

FIG 3. Stratification of patients based on MSRS analysis for splits in post-EC $100 \%$. Kaplan-Meier curves for high and low change groups for PFS $(A)$ and $O S(B)$.

and may serve as a valuable biomarker of early tumor progression, which may, in part, reflect infiltration in patients with HGGs.

In this study, we also demonstrate that the prognostic value of EC appears highly robust to the EC threshold used. Although different thresholds for EC showed slightly different associations with PFS and OS, the overlap in confidence intervals indicates that the differences among the thresholds are small and may not be clinically meaningful. EC robustness indicates that a global measure of FLAIR border sharpness may be just as sensitive as one that focuses on the "vaguest" regions of the border following treatment with bevacizumab. This is in line with previous studies that have shown that patterns of nonenhancing tumor progression are diffuse rather than focal following treatment with bevacizumab. ${ }^{9}$ EC consistency pattern may not be present in other clinical scenarios or following treatment with other chemotherapeutic agents in which more focal regions of tumor growth have been identified and different EC levels may have different prognostic values.

This study is the first to use a $3 \mathrm{D}$ texture analysis technique to quantify the sharpness of the FLAIR hyperintense border and demonstrate an association with PFS and OS in patients with HGG treated with bevacizumab. This method of 3D edge extraction may increase the level of precision and the reliability of FLAIR border pattern assessment relative to visual ratings used in previous studies. Such a measure may be particularly useful in large-scale clinical trials of antiangiogenic treatments in which standardized, high-throughput image analysis methods are critical and expert readings may introduce systematic bias and be too labor-intensive. This measure may eventually serve as an adjunct to standard qualitative MR imaging interpretation, especially in settings in which neuro-oncology volume and expertise in nuanced neuroradiology interpretation may be lower.

There are some limitations to this study. First, our sample size was relatively small, and all patients were recruited from the same institution. Second, we included a heterogeneous group of patients with HGG (ie, grade III and GBM). Given recent evidence that molecular information (eg, IDH status) may be as important or more important for predicting OS than histopathologic diagnosis, ${ }^{24}$ we included both groups. Unfortunately, we did not have molecular information on many patients (On-line Table). Although IDH status was available for 17 of our patients, only 3 patients had $I D H$-mutant status, precluding any meaningful analysis of these data. As a result, we were not able to determine how EC patterns relate to different molecular subtypes or how our imaging variables could be used in combination with molecular status to predict survival in patients with HGGs. These latter investigations are currently underway at our institution. Finally, the current resolution of MR imaging may be too low to adequately capture microscopic tumor infiltration in the brain. Although we propose that tumor infiltration is a likely reason for decreases in EC postbevacizumab, higher resolution MR imaging will help to increase the value of quantitative MR imaging metrics such as ours.

\section{CONCLUSIONS}

Our study introduces a quantitative measurement of FLAIR border patterns that may serve as a biomarker for detecting early nonenhancing tumor progression following treatment with bev- 
acizumab in HGG. However, whether this measure has clinical utility following treatment with bevacizumab or other antiangiogenic agents will need to be established in further investigation with larger patient cohorts that are stratified according to molecular subtype and other important biologic and treatment-related variables.

\section{ACKNOWLEDGMENTS}

We thank the patients at the University of California, San Diego Moores Cancer Center Neuro-Oncology Program for their generous participation.

Disclosures: Naeim Bahrami-RELATED: Grant: American Cancer Society, Comments: RSG-15-229-01-CCE.* Tyler M. Seibert-UNRELATED: Grants/Grants Pending: Varian Medical Systems, Comments: coinvestigator on a grant to study MRI distortion effects on radiation treatment planning*; Payment for Development of Educational Presentations: WebMD, Comments: I received honoraria for educational materials for physicians, no sponsored promotions. Jona A. HattangadiGluth—UNRELATED: Grants/Grants Pending: Varian Medical Systems, Comments: I have a research grant from Varian Medical Systems outside the scope and unrelated to the current work.* Anders Dale-UNRELATED: Board Membership: Human Longevity, CorTechs Labs, Comments: I serve as a member of Scientific Advisory Boards of Human Longevity and the CorTechs Labs. The terms of these arrangements have been reviewed by and approved by the University of California, San Diego, in accordance with its conflict of interest policies; Employment: Oslo University Hospital, Comments: appointed as Professor II (equal to an adjunct appointment within the University of California system). Annual compensation is NOK 131,963 Kr (approximately $\$ 16,595$ annually at the current exchange rate). The terms of these arrangements have been reviewed by and approved by University of California, San Diego, in accordance with its conflict of interest policies; Grants/Grants Pending: GE Healthcare, Comments: I receive funding through research grants with GE Healthcare. The terms of these arrangements have been reviewed by and approved by University of California, San Diego, in accordance with its conflict of interest policies*; Stock/ Stock Options: CorTechs Labs, Comments: I am a founder of and hold equity in CorTechs Labs. The terms of these arrangements have been reviewed by and approved by University of California, San Diego, in accordance with its conflict of interest policies. Carrie R. McDonald-RELATED: Grant: American Cancer Society, Comments: RSG-15-229-01-CCE.* *Money paid to the institution.

\section{REFERENCES}

1. Wen PY, Kesari S. Malignant gliomas in adults. N Engl J Med 2008; 359:492-507 CrossRef Medline

2. Wen PY, Macdonald DR, Reardon DA, et al. Updated response assessment criteria for high-grade gliomas: Response Assessment in Neuro-Oncology working group. J Clin Oncol 2010;28:1963-72 CrossRef Medline

3. Chinot OL, Macdonald DR, Abrey LE, et al. Response assessment criteria for glioblastoma: practical adaptation and implementation in clinical trials of antiangiogenic therapy. Curr Neurol Neurosci Rep 2013;13:347 CrossRef Medline

4. Macdonald DR, Cascino TL, Schold SC, et al. Response criteria for phase II studies of supratentorial malignant glioma. J Clin Oncol 1990;8:1277-80 CrossRef Medline

5. Galldiks N, Rapp M, Stoffels G, et al. Response assessment of bevacizumab in patients with recurrent malignant glioma using [18F] fluoroethyl-L-tyrosine PET in comparison to MRI. Eur J Nucl Med Mol Imaging 2013;40:22-33 CrossRef Medline

6. Kothari PD, White NS, Farid N, et al. Longitudinal restriction spectrum imaging is resistant to pseudoresponse in patients with highgrade gliomas treated with bevacizumab. AJNR Am J Neuroradiol 2013;34:1752-57 CrossRef Medline

7. Jeyaretna DS, Curry WT Jr, Batchelor TT, et al. Exacerbation of cerebral radiation necrosis by bevacizumab. J Clin Oncol 2011;29: e159-62 CrossRef Medline

8. Pope WB, Lai A, Nghiemphu P, et al. MRI in patients with highgrade gliomas treated with bevacizumab and chemotherapy. Neurology 2006;66:1258-60 CrossRef Medline

9. Pope WB, Xia Q, Paton VE, et al. Patterns of progression in patients with recurrent glioblastoma treated with bevacizumab. Neurology 2011;76:432-37 CrossRef Medline

10. Norden AD, Young GS, Setayesh K, et al. Bevacizumab for recurrent malignant gliomas: efficacy, toxicity, and patterns of recurrence. Neurology 2008;70:779-87 CrossRef Medline

11. Gonzalez J, Kumar AJ, Conrad CA, et al. Effect of bevacizumab on radiation necrosis of the brain. Int J Radiat Oncol Biol Phys 2007;67: 323-26 CrossRef Medline

12. Hattingen E, Jurcoane A, Daneshvar K, et al. Quantitative T2 mapping of recurrent glioblastoma under bevacizumab improves monitoring for non-enhancing tumor progression and predicts overall survival. Neuro Oncol 2013;15:1395-404 CrossRef Medline

13. Pope WB, Qiao XJ, Kim HJ, et al. Apparent diffusion coefficient histogram analysis stratifies progression-free and overall survival in patients with recurrent GBM treated with bevacizumab: a multicenter study. J Neurooncol 2012;108:491-98 CrossRef Medline

14. Huang RY, Rahman R, Ballman KV, et al. The impact of T2 FLAIR evaluation per RANO criteria on response assessment of recurrent glioblastoma patients treated with bevacizumab. Clin Cancer Res 2016;22:575-81 CrossRef Medline

15. Sathornsumetee S, Desjardins A, Vredenburgh JJ, et al. Phase II trial of bevacizumab and erlotinib in patients with recurrent malignant glioma. Neuro Oncol 2010;12:1300-10 CrossRef Medline

16. Quant EC, Norden AD, Drappatz J, et al. Role of a second chemotherapy in recurrent malignant glioma patients who progress on bevacizumab. Neuro Oncol 2009;11:550-55 CrossRef Medline

17. Drabycz S, Roldán G, de Robles $P$, et al. An analysis of image texture, tumor location, and MGMT promoter methylation in glioblastoma using magnetic resonance imaging. Neuroimage 2010;49:1398-405 CrossRef Medline

18. Carpentier A, McNichols RJ, Stafford RJ, et al. Laser thermal therapy: real-time MRI-guided and computer-controlled procedures for metastatic brain tumors. Lasers Surg Med 2011;43:943-50 CrossRef Medline

19. Kim JW, Park CK, Park SH, et al. Relationship between radiological characteristics and combined $1 \mathrm{p}$ and $19 \mathrm{q}$ deletion in World Health Organization grade III oligodendroglial tumours. J Neurol Neurosurg Psychiatry 2011;82:224-27 CrossRef Medline

20. Nowosielski M, Wiestler B, Goebel G, et al. Progression types after antiangiogenic therapy are related to outcome in recurrent glioblastoma. Neurology 2014;82:1684-92 CrossRef Medline

21. Taillibert S, Vincent LA, Granger B, et al. Bevacizumab and irinotecan for recurrent oligodendroglial tumors. Neurology 2009;72:1601-06 CrossRef Medline

22. Artzi M, Bokstein F, Blumenthal DT, et al. Differentiation between vasogenic-edema versus tumor-infiltrative area in patients with glioblastoma during bevacizumab therapy: a longitudinal MRI study. Eur J Radiol 2014;83:1250 -56 CrossRef Medline

23. Kinoshita M, Sakai M, Arita H, et al. Introduction of high throughput magnetic resonance T2-weighted image texture analysis for WHO grade 2 and 3 gliomas. PLoS One 2016;11:e0164268 CrossRef Medline

24. Delfanti RL, Piccioni DE, Handwerker J, et al. Imaging correlates for the 2016 update on WHO classification of grade II/III gliomas: implications for IDH, 1p/19q and ATRX status. J Neurooncol 2017;135: 601-09 CrossRef Medline

25. McDonald CR, Delfanti RL, Krishnan AP, et al. Restriction spectrum imaging predicts response to bevacizumab in patients with highgrade glioma. Neuro Oncol 2016;18:1579-90 CrossRef Medline

26. Jovicich J, Czanner S, Greve D, et al. Reliability in multi-site structural MRI studies: effects of gradient non-linearity correction on phantom and human data. Neuroimage 2006;30:436-43 CrossRef Medline

27. Nachimuthu DS, Baladhandapani A. Multidimensional texture characterization: on analysis for brain tumor tissues using MRS and MRI. J Digit Imaging 2014;27:496-506 CrossRef Medline

28. Li X, Xia H, Zhou Z, et al. 3D texture analysis of hippocampus based on MR images in patients with Alzheimer disease and mild cogni- 
tive impairment. In: Proceedings of the 3rd International Conference on Biomedical Engineering and Informatics, Yantai, China. October 16-18, 2010;1:1-4

29. Suoranta S, Holli-Helenius K, Koskenkorva P, et al. 3D texture analysis reveals imperceptible MRI textural alterations in the thalamus and putamen in progressive myoclonic epilepsy type 1, EPM1. PLoS One 2013;8:e69905 CrossRef Medline

30. Zhang J, Yu C, Jiang G, et al. 3D texture analysis on MRI images of Alzheimer's disease. Brain Imaging Behav 2012;6:61-69 CrossRef Medline

31. Ellingson BM, Cloughesy TF, Lai A, et al. Quantitative volumetric analysis of conventional MRI response in recurrent glioblastoma treated with bevacizumab. Neuro Oncol 2011;13:401-09 CrossRef Medline

32. de Groot JF, Fuller G, Kumar AJ, et al. Tumor invasion after treatment of glioblastoma with bevacizumab: radiographic and pathologic correlation in humans and mice. Neuro Oncol 2010;12:233-42 CrossRef Medline

33. Narayana A, Kelly P, Golfinos J, et al. Antiangiogenic therapy using bevacizumab in recurrent high-grade glioma: impact on local control and patient survival. J Neurosurg 2009;110:173-80 CrossRef Medline

34. Claes A, Idema AJ, Wesseling P. Diffuse glioma growth: a guerilla war. Acta Neuropathol 2007;114:443-58 CrossRef Medline 